\title{
PENGARUH TERAPI TERTAWA TERHADAP PENURUNAN TEKANAN HUBUNGAN PERUBAHAN FISIK DENGAN HARGA DIRI PADA WANITA MENOPAUSE DI PUSKESMAS SUKAMERINDU KOTA BENGKULU
}

\author{
Dwi Agususanti, Novega
}

\author{
STIKES Bhakti Husada Bengkulu \\ Jl. Kinibalu 8 Kebun Tebeng Bengkulu Telp (0736) 23422 \\ Email : stikesbh03@gmail.com
}

\begin{abstract}
Abstrak
Menopause merupakan diagnosis yang ditegakkan secara retrospektif setelah wanita tidak mengalami haid secara berturut-turut hingga 12 bulan lamanya. Masalah penelitian ini masih banyaknya wanita yang memiliki harga diri kurang baik saat mengalami menopause dengan tujuan diketahuinya hubungan perubahan fisik dengan harga diri pada wanita menopause di Puskesmas Sukamerindu Kota Bengkulu.

Penelitian bersifat kuantitatif dengan pendekatan Cross Sectional dengan jumlah sampel sebanyak 66 orang wanita. Hasil penelitian diperoleh terdapat $37(56,1 \%)$ atau sebagian besar responden, dengan terjadi perubahan, terdapat $31(47,0 \%)$ atau hampir sebagian besar responden, dengan harga diri rendah, dengan nilai $\rho=0,002 \leq 0,05$, sehingga disimpulkan ada hubungan perubahan fisik dengan harga diri pada wanita menopause di Puskesmas Sukamerindu Kota Bengkulu.

Hasil penelitian diharapakan dapat memberikan masukan bagi tempat penelitian agar dapat meningkatkan harga diri pada wanita yang mengalami menopause dengan cara memberikan pengetahuan baik kepada responden ataupun keluarga.
\end{abstract}

Kata Kunci : Menopause, Harga Diri, Wanita Menopause

\section{CHANGE IN PHYSICAL RELATIONSHIP WITH PRIDE ON MENOPAUSAL WOMEN AT PUSKESMAS SUKAMERINDU BENGKULU CITY}

\begin{abstract}
Menopause is the diagnosis that is enforceable retrospectively after she did not experience menstruation in berturut-turut until 12 months. Research problem it is still the number of women who have self esteem less well when going through menopause for the purpose he knew the relationship physical changes with pride on menopausal women at Puskesmas Sukamerindu Bengkulu City. Quantitative research is approaching cross sectional by the number of samples from 66 women .There are 37 research obtained $(56,1 \%)$ or the majority of respondents, with evidence for changes, there are 31 (47,0\%) or nearly the majority of respondents, with low self esteem, with the $\rho=0,002 \leq 0,05$, it can be concluded that there is a change in physical for themselves in postmenopausal women at Puskesmas Sukamerindu Bengkulu City.

The research is expected to provide input for the research to increase prices for a woman whose period menopause by granting of knowledge of good kin to respondents

Keywords : Menopause, Self-Esteem, Postmenopausal Women
\end{abstract}




\section{PENDAHULUAN}

Menopause merupakan berhentinya haid secara permanen dalam periode menstruasi yang terakhir pada seorang wanita. Menopause merupakan diagnosis yang ditegakkan secara retrospektif setelah wanita tidak mengalami haid secara berturut-turut hingga 12 bulan lamanya. Menopause akan terjadi disaat seorang wanita tidak lagi menghasilkan ovum sehingga perlahan menstruasi akan menjadi tidak teratur dan akhirnya terhenti (Mulyani, 2013).

Menopause umumnya terjadi pada rentang usia 48-55 tahun dengan ratarata usia 51 tahun (Yulizawati, 2016). Dengan bertambahnya usia akan muncul tanda berupa perubahan organ tubuh seperti tidak teraturnya haid, sulit tidur, pusing, mudah tersinggung, mudah marah, sulit tidur, mudah curiga. Hal ini terjadi karena perubahan hormonal di dalam tubuh yaitu pembentukan hormon estrogen dan progesteron dari ovarium wanita telah berkurang. Hal ini yang menyebabkan siklus menstruasi menjadi tidak teratur, ini dijadikan petunjuk terjadinya menopause (Mulyani, 2013).

Tahun 2030, jumlah perempuan di seluruh dunia yang memasuki masa menopause diperkirakan mencapai 1,2 miliar orang (WHO:2014). Di Indonesia, pada tahun 2025 diperkirakan akan ada 60 juta perempuan menopause. Pada tahun 2016 saat ini di Indonesia baru mencapai 14 juta perempuan menopause atau $7,4 \%$ dari total populasi yang ada. Angka harapan hidup perempuan melonjak dari 40 tahun pada tahun 1930 menjadi 67 tahun pada tahun 1998. Sementara perkiraan umur rata-rata usia menopause di Indonesia adalah 48 tahun. Peningkatan usia harapan hidup menyebabkan jumlah perempuan yang mengalami menopause semakin banyak (Kemenkes RI. 2014).

Usia menopause, alat-alat reproduksi wanita sudah tidak berfungsi dengan baik. Sesuai dengan perubahan usia, fungsi tubuh pun mengalami perubahan tanpa terkecuali fungsi seksual. Pada usia 60 tahun, kebutuhan peksual, pola, dan penampilan seorang wanita tidak lagi sama seperti 30 tahun yang lalu. Hal ini tentu saja mempengaruhi harga diri wanita tersebut, misalnya perasaan kurang percaya lagi unt uk tampil di hadapan suami (Yulizawati, 2016).

Salah satu faktor yang berpengaruh pada munculnya kecemasan dan depresi pada wanita dalam menghadapi menopause adalah ganguan Harga Diri. Perubahan-perubahan yang terjadi baik secara fisik, psikis, maupun seksual akan menyebabkan wanita yang sedang menghadapi menopause khawatir dan cemas. Oleh karena itu, diperlukan kemauan untuk menerima perubahan diri secara realitas sehingga memunculkan penilaian yang positif terhadap diri, menerima, dan menyukai bagian tubuh yang dimiliki agar dapat terhindar dari rasa cemas. (Kahesi dkk, 2013).

Wanita yang sedang mengalami menopause digambarkan banyak mengalami masalah antara lain merasakan pergeseran dan perubahanperubahan fisik dan psikis yang memengaruhi kualitas hidup pada wanita yang telah memasuki masa menopause. Kualitas hidup wanita menopause akan memengaruhi penyesuaian diri dengan perubahan fisik maupun pengaruhpengaruh psikis yang menyertainya, wanita menopause masih harus menyesuaikan diri dengan lingkungan di luar dirinya.

Berdasarkan Penelitian Putri dkk (2012) di Surabaya menunjukkan bahwa, terdapat hubungan antara penerimaan diri dengan depresi selama perimenopause. Seseorang dalam mencapai suatu Harga Diri harus dapat menjalankan penerimaan atas dirinya. Ketika penerimaan diri rendah maka depresi pada wanita perimenopause tinggi, dan begitu pula sebaliknya, jika penerimaan diri tinggi maka depresi 
pada wanita perimenopause rendah. Penerimaan diri memegang kedudukan 50 persen sebagai penyebab depresi.

Puskesmas Sukamerindu Kota Bengkulu merupakan puskesmas rawat jalan, yang terdiri dari ruang tindakan, ruang kesehatan anak dan imunisasi, ruang kesehatan ibu dan anak, ruang kesehatan gigi dan mulut, ruang farmasi dan ruang laboratorium. Berdasarkan data yang diperoleh dari Puskesmas Sukamerindu Kota Bengkulu jumlah wanita menopause yang berobat pada tahun 2016 sebanyak 128 pasein, tahun 2017 sebanyak 197 orang pasien (Medical Record Puskesmas Sukamerindu Kota Bengkulu, 2017).

Hasil survey awal yang dilakukan tanggal 20 Desember 2017 dari wawancara terhadap 7 orang wanita yang telah mengalami menopause, 5 orang wanita mengatakan setelah mengalami menopause terjadi perubahan pada diri, seperti mulai dari kondisi tubuh yang menurun, mudah lelah, payudara sudah tidak kencang seperti dahulu ketika sebelum menopause, jantung berdebar-debar, insomnia (susah tidur), depresi, gangguan libido (hasrat seks), berat badan bertambah, nyeri tulang dan otot, cepat lelah, sulit konsentrasi dan mudah lupa serta kurang tenaga. Sedangkan 2 orang lansia mengatakan tidak mempermasalahkan terjadi menopause karena sudah menjadi kodrat bagi seorang wanita.

Dampak bagi wanita menopause tersebut adalah menjadi cemas, takut, dan depresi karena wanita beranggapan bahwa menopause merupakan masa suram dimana wanita tidak berdaya lagi dalam melayani hasrat seksual suaminya. Ditambah lagi pihak kesehatan yang ada Puskesmas Sukamerindu Kota Bengkulu ini belum pernah melakukan promosi atau penyuluhan tentang masalah menopause. Ini membuat masyarakat beranggapan bahwa menopause adalah suatu masalah yang harus dihindari padahal ini merupakan suatu keadaan normal yang harus dialami oleh setiap wanita

\section{METODE}

Penelitian ini bersifat kuantitatif menggunakan penelitian analisis dengan pendekatan Cross Sectional. Jenis penelitian ini digunakan untuk mengetahui hubungan antar kedua variabel, dimana pengukuran kedua variabel tersebut dilakukan pada saat yang bersamaan (Notoajmodjo, 2010). Teknik yang dipakai untuk mengambil sampel pada penelitian ini adalah teknik sampel accidental sampling. dimana pengambilan sampel secara aksidental (accidental) dengan mengambil kasus atau responden yang kebetulan ada atau tersedia di suatu tempat sesuai dengan konteks penelitian dengan jumlah sampel sebanyak 66 orang responden. Teknik pengumpulan data dalam penelitian ini adalah dengan cara mengumpulkan data primer dan data sekunder

\section{HASIL}

Analisis univariat digunakan untuk mendapatkan gambaran dari variabel yang diteliti. Variabel independen dalam penelitian ini adalah perubahan fisik, sedangkan variabel dependen harga diri.

\section{Tabel 2 Diketahuinya distribusi Perubahan Fisik di Puskesmas Sukamerindu Kota Bengkulu}

\begin{tabular}{llcc}
\hline No & Menopause & Frekuensi & Persentase \\
\hline 1. & $\begin{array}{l}\text { Terjadi } \\
\text { Perubahan }\end{array}$ & 37 & 56,1 \\
2. & $\begin{array}{l}\text { Tidak Terjadi } \\
\text { Perubahan }\end{array}$ & 29 & 43,9 \\
\hline & Jumlah & 66 & 100 \\
\hline
\end{tabular}

Hasil penelitian di atas menunjukkan, terdapat $37(56,1 \%)$ atau sebagian besar 
responden, dengan terjadi perubahan di Puskesmas Sukamerindu Kota Bengkulu.

Tabel 3 Distribusi Frekuensi Harga Diri Pada Wanita Di Puskesmas Sukamerindu Kota Bengkulu

\begin{tabular}{clcc}
\hline No & Harga Diri & $\begin{array}{c}\text { Frekue } \\
\text { nsi }\end{array}$ & $\begin{array}{c}\text { Persentas } \\
\text { e }\end{array}$ \\
\hline 1. & $\begin{array}{l}\text { Harga Diri } \\
\text { Rendah }\end{array}$ & 31 & 47,0 \\
2. & $\begin{array}{l}\text { Harga Diri } \\
\text { Tinggi }\end{array}$ & 35 & 53,0 \\
\hline & Jumlah & 66 & 100 \\
\hline
\end{tabular}

Hasil penelitian di atas menunjukan, terdapat $31(47,0 \%)$ atau hampir sebagian besar responden, dengan harga diri rendah di Puskesmas Sukamerindu Kota Bengkulu

Analisis bivariat digunakan untuk mengetahui hubungan dengan harga perubahan fisik diri pada wanita menopause di Puskesmas Sukamerindu Kota Bengkulu, dengan menggunakan analisis statistik uji Chi-square.

Tabel 4 Hubungan Perubahan Fisik Dengan Harga Diri Pada Wanita Menopause Di Puskesmas Sukamerindu Kota Bengkulu

\begin{tabular}{|c|c|c|c|c|c|c|c|}
\hline \multirow{3}{*}{$\begin{array}{c}\text { Perubahan } \\
\text { Fisik }\end{array}$} & \multicolumn{4}{|c|}{ Harga Diri } & & & \multirow{3}{*}{$\mathbf{P}$} \\
\hline & \multicolumn{2}{|c|}{$\begin{array}{c}\text { Harga } \\
\text { Diri } \\
\text { Rendah }\end{array}$} & \multicolumn{2}{|c|}{$\begin{array}{c}\text { Harga } \\
\text { Diri } \\
\text { Tinggi }\end{array}$} & \multicolumn{2}{|c|}{ Total } & \\
\hline & $\mathrm{N}$ & $\%$ & $\mathrm{~N}$ & $\%$ & $\mathrm{~N}$ & $\%$ & \\
\hline $\begin{array}{l}\text { Terjadi } \\
\text { Perubahan }\end{array}$ & 23 & $\begin{array}{l}64 \\
, 9\end{array}$ & 13 & $\begin{array}{l}35 \\
1\end{array}$ & 37 & $\begin{array}{c}10 \\
0\end{array}$ & \\
\hline $\begin{array}{l}\text { Tidak } \\
\text { Terjadi } \\
\text { Perubahan }\end{array}$ & 7 & $\begin{array}{r}24 \\
, 1\end{array}$ & 22 & $\begin{array}{r}75 \\
, 9\end{array}$ & 29 & $\begin{array}{c}10 \\
0\end{array}$ & $\begin{array}{l}0,0 \\
02\end{array}$ \\
\hline Total & 31 & $\begin{array}{l}47 \\
, 0\end{array}$ & 35 & $\begin{array}{r}53 \\
, 0\end{array}$ & 66 & $\begin{array}{c}10 \\
0\end{array}$ & \\
\hline
\end{tabular}

Berdasarkan hasil penelitian, dari 66 responden, diketahui bahwa 37 responden terjadi perubahan fisik, $13 \quad(35,1 \%)$ responden dengan harga diri tinggi. Dari 29 responden dengan tidak terjadi perubahan fisik, $7(24,1 \%)$ responden dengan harga diri rendah. Berdasarkan hasil analisis ChiSquare diperoleh nilai $\rho=0,002 \leq 0,05$, sehingga dapat disimpulkan bahwa $\mathrm{Ha}$ diterima, artinya ada hubungan perubahan fisik dengan harga diri pada wanita menopause di Puskesmas Sukamerindu Kota Bengkulu.

\section{PEMBAHASAN}

\section{Distribusi Frekuensi Perubahan Fisik}

Hasil penelitian yang diperoleh data bahwa terdapat, terdapat $37(56,1 \%)$ atau sebagian besar responden terjadi perubahan fisik di Puskesmas Sukamerindu Kota Bengkulu. Hasil penelitian yang diperoleh sebagaian besar responden terjadi perubahan fisik. Responden mengatakan mengalami siklus perdarahan yang keluar dari vagina tidak teratur, mengalami rasa panas yang menyebar dari wajah hingga seluruh tubuh terjadi pada dada, wajah, dan kepala dan timbulnya warna kemerahan pada kulit dan keluarnya keringat, responden mengatakan vagina menjadi kering dan tidak elastis lagi, responden juga mengatakan mengalami peningakatan berat badan. Beberapa responden juga mengatakan mengalami nyeri di sendi dann tulang belang

Responden mengatakan mengalami menopause pada usia rata-rata diatas 55 tahun. Menopause merupakan keadaan dimana seorang perempuan tidak lagi mengalami menstruasi yang terjadi pada rentang usia 50 sampai 59 tahun. Pada masa ini sangat kompleks bagi perempuan karena akan mengalami perubahan kesehatan fisik yang akan mempengaruhi kesehatan psikologisnya.

Namun banyak wanita yang menganggap bahwa menopause merupakan suatu hal yang menakutkan. Hal ini mungkin berasal dari suatu pemikiran bahwa dirinya akan menjadi tua, tidak sehat, dan tidak cantik lagi. Selain itu, wanita dalam masa menopause mengalami perubahan besar dalam kehidupannya dan beradaptasi terhadap perubahan peran dalam keluarga 
maupun masyarakat, serta harus menghadapi perubahan tubuh dan harapannya dalam hidup

Hasil penelitian yang diperoleh data bahwa terdapat, terdapat $29(43,9 \%)$ atau hampir sebagian besar responden, tidak terjadi perubahan fisik di Puskesmas Sukamerindu Kota Bengkulu. Responden mengatakan tidak mengalami perubahan fisik yang sangat mengangu, responden hanya mengatakan terjadinya menopause mambuat vagina menjadi kering dan tidak elastis.

\section{Distribusi Frekuensi Harga Diri}

Hasil penelitian di atas menunjukan, terdapat $31(47,0 \%)$ atau hampir sebagian besar responden, dengan harga diri rendah di Puskesmas Sukamerindu Kota Bengkulu. Hasil penelitian yang diperolah bahwa responden menjelaskan sering meras cemas saat terjadi sesuatu pada diri setalah mengalami menopause, terjadi penurunan harga diri, tidak memiliki motivasi dalam melaksanakan pekerjaan. Responden mengatakan sering mengalami emosi yang labil setalah mengalami menopause, responden juga mengatakan tidak dapat menyesuikan diri dengan lingkungan sekitar.

Gejala saat menopause adalah perasaan menurunnya harga diri karena menurunnya daya tarik fisik dan seksual, mereka merasa tidak dibutuhkan oleh suami dan anak-anak mereka, serta merasa kwhilangan feminitas karena fungsi reproduksi yang menurun juga mengatakan bahwa seorang yang mengalami menopause sering sulit berkonsentrasi, sering lupa, kesepian, suasana hati tidak menentu dan sering merasa cemas.

Hasil penelitian di atas menunjukan, terdapat $35(53 \%)$ atau sebagian besar responden, dengan harga diri tinggi di Puskesmas Sukamerindu Kota Bengkulu. Responden menjelaskan walaupun telah mengalami menopause tidak terjadi perubahan pada dirinya. Responden tetap melakukan aktivitas seperti biasanya, emosi selalu stabil, harga diri baik.

Perubahan yang terjadi selama masa transisi inilah yang membutuhkan penyesuaian dan tidak semua wanita dapat menyesuaikan diri dengan baik selama menopause. Menurut Ibrahim (2015) sebagian orang memandang menopause sebagai masa kritis karena pada masa ini wanita mengalami penurunan jumlah hormon estrogen yang nantinya akan menyebabkan perubahan-perubahan fisik yang bersifat eksternal. Perubahanperubahan fisik yang bersifat eksternal dapat dilihat dari perubahan penampilan kewanitaan yang menurun seperti payudara tidak kencang, bibir dan kulit menjadi kering dan kurang halus, rambut beruban, menipis dan mudah rontok, selaput bening mata menjadi lebih kering, lekuk tubuh menjadi rata, dan tubuh relatif menjadi lebih gemuk.

Perubahan dan gejala fisik yang terjadi ketika menopause seringkali juga disertai dengan beberapa gejala psikologis. Papalia (2015) mengungkapkan bahwa gejala-gejala psikologis yang muncul dapat meliputi stres, frustasi, dan adanya penolakan terhadap menopause. Hurlock (2010) juga menyatakan bahwa pada masa menopause wanita menjadi lebih mudah tersinggung, tertekan, gelisah, gugup, kesepian, tidak sabar, gangguan konsentrasi, tegang, cemas, bahkan depresi. Hal ini sejalan dengan hasil penelitian Maartens (2012) yang menyatakan bahwa dari hasil self report yang berkaitan dengan depressed mood pada wanita menopause ditemukan bahwa $36 \%$ wanita premenopause, $47 \%$ wanita perimenopause, dan $46 \%$ postmenopause mengalami depressed mood.

Penelitian yang dilakukan oleh Robertson (dalam Christiani, 2012) di Menopause Clinic Australia juga menemukan bahwa dari 300 pasien usia menopause terdapat $31,3 \%$ pasien mengalami kecemasan dan depresi. Kecemasan dan depresi yang dialami wanita menopause umumnya berkaitan dengan kesulitan-kesulitan emosi yang mereka alami pada saat menyesuaikan diri dengan berbagai perubahan hormon dan psikologis yang terjadi selama menopause (Becker, 
Orr, Weizman, 2007). Simptom depresi yang terjadi selama menopause berkaitan juga dengan sikap yang negatif terhadap menopause yang berujung pada rendahnya harga diri pada wanita. Wanita yang memiliki sikap negatif terhadap menopause seperti merasa tua, kurang menarik, dan tidak nyaman dengan gejala menopause yang muncul seringkali dikaitkan dengan munculnya banyak keluhan selama menopause dibandingkan dengan wanita dengan sikap positif. Begitu juga wanita dengan harga diri yang rendah menunjukkan penyesuaian diri yang lebih sulit terhadap menopause dibandingkan dengan wanita dengan harga diri yang tinggi. Mereka lebih sering mengalami kecemasan terkait dengan gejala-gejala menopause. Selain itu, mereka juga kurang percaya diri dan lebih sering mengeluhkan berbagai perubahan yang terjadi pada dirinya

\section{Hubungan Perubahan Fisik Dengan Harga Diri Pada Wanita Menopause}

Berdasarkan hasil penelitian, dari 66 responden, diketahui bahwa 37 responden dengan terjadi perubahan, $13 \quad(35,1 \%)$ responden dengan harga diri tinggi. Hasil penelitiian yang diperoleh respoden memiliki pengetahuan yang baik tentang kedaan wanita yang mengalami menopause sehingga respoden sudah siap dan mengetahui tetang menopause. Faktor lain yang mempengaruhi adalah sikap responden dan keluarga yang baik.

Pada masa menopause, tidak ada orang yang bisa lepas sama sekali dari rasa waswas dan cemas, termasuk para lansia menopause. Ketegangan perasaan atau stress selalu beredar dalam lingkungan pekerjaan, pergaulan sosial, kehidupan rumah tangga, dan bahkan menyelusup ke dalam tidur. Demikian juga dengan gejala depresi di masa menopause. Perempuan merasa tertekan karena kehilangan seluruh perannya sebagai perempuan dan harus menghadapi masa tuanya
Kondisi emosional yang tidak stabil ini akibat pengaruh perubahan hormon dalam tubuh atau karena faktor yang sifatnya sangat individual. Selain itu, fase menopause sering berbarengan dengan keadaan menegangkan lain dalam kehidupan perempuan seperti merawat orang tua lanjut usia, memasuki masa pensiun, melihat anakanak tumbuh dewasa dan meninggalkan rumah serta penyesuaian-penyesuaian lain dalam kehidupan setengah baya.

Berdasarkan hasil penelitian, dari 29 responden dengan tidak terjadi perubahan fisik, $7(24,1 \%)$ responden dengan harga diri rendah. Hasil penelitian yang diperolah bahwa faktor beragamnya faktor penyebab harga diri rendah. Responden menjelaskan kurang perhatian dan dukungan dari keluarga dalam melakukan aktivitas, kurang dapat bergaul di lingkungan sekitar. Beberapa responden menjelasakan keluarga hanya menginginkan responden hanya berada dirumah karena usia yang sudah lanjut.

Individu dengan harga diri yang baik cenderung menunjukkan keberhasilan yang diraihnya sebagai upaya dan kualitas pribadinya. Harga diri adalah rasa dihormati, diterima, dan bernilai. Ketika seseorang berusia lanjut, masyarakat cenderung beranggapan bahwa menjadi lansia membuat seseorang itu menjadi tidak berharga. Hal ini dapat mempengaruhi persepsi lansia terhadap harga dirinya baik atau tidak. Penolakan dan harapan dari orang-orang terdekat di saat usia lanjut sangat mempengaruhi harga diri seseorang seperti yang diutarakan (Stuart dan Sudden, 2012).

$$
\text { Penurunan harga diri dapat }
$$

disebabkan karena wanita yang sudah menopause mengalami banyak perubahan, baik fisik maupun psikis yang dapat mempengaruhi berbagai kehidupan. Wanita yang mengalami menopause menganggap menjadi salah satu tanda bahwa tubuhnya tidak semenarik dulu, sehingga ada kekhawatiran tertentu, salah satunya adalah pasangan hidup akan kurang bergairah padanya. Menopause menjadi tanda bahwa 
dia semakin tua dengan tubuh yang tidak segar, kulit yang keriput, dan sensitifitas yang semakin meningkat. Perubahan fisik yang terjadi mengakibatkan timbulnya perasaan tak berharga, tidak berarti dalam hidup. Perasaan itulah yang seringkali dirasakan wanita pada masa menopause, sehingga sering mempengaruhi harga diri wanita pada masa menopause (Santrock, 2012).

Berdasarkan hasil penelitian, dari 66 responden, diketahui bahwa 37 responden terjadi perubahan fisik, $13 \quad(35,1 \%)$ responden dengan harga diri rendah. Dari 29 responden dengan tidak terjadi perubahan fisik, $22(75,9 \%)$ responden dengan harga diri tinggi. Berdasarkan hasil analisis ChiSquare diperoleh nilai $\rho=0,002 \leq 0,05$, sehingga dapat disimpulkan bahwa $\mathrm{Ha}$ diterima, artinya ada hubungan perubahan fisik dengan harga diri pada wanita menopause di Puskesmas Sukamerindu Kota Bengkulu.

\section{SIMPULAN}

a. Sebagian besar responden, terjadi perubahan fisik di Puskesmas Sukamerindu Kota Bengkulu.

b. Hampir sebagian besar responden, dengan harga diri rendah di Puskesmas Sukamerindu Kota Bengkulu

c. Ada hubungan perubahan fisik dengan harga diri pada wanita menopause di Puskesmas Sukamerindu Kota Bengkulu.

\section{SARAN}

\section{Teoritis}

Dengan adanya hasil penelitian ini diharapkan kepada semua petugas puskesmas dapat lebih memahami penerapan perubahan fisik dengan harga diri pada wanita menopause. Kemudian dapat bermanfaat menambah literatur atau bahan tambahan pengetahuan bagi mahasiswa STIKes Bhakti Husada Bengkulu khususnya perubahan fisik dengan harga diri pada wanita menopause.

\section{Praktis}

Hasil penelitian diharapakan dapat memberikan masukan bagi tempat penelitian agar dapat meningkatkan harga diri pada wanita yang terjadi perubahan fisik dengan cara memberikan pengetahuan baik kepada responden ataupun keluarga dengan cara memberikan pendidikan kesehatan. Selain itu pihak puskesmas lebih meningkatakan lagi kegiatan yang dilakukan pada posyandu lansia, sepe 61 mengadakan terapi modalitas kepa lansia yang mengalami menopause, sehingga dapat meningkatkan harga diri pada lansia.

\section{DAFTAR PUSTAKA}

Abdillah Fatkhul Wahab. 2014. Pengaruh Terapi Aktivitas Kelompok (TAK) Terhadap Peningkatan Harga Diri Dan Motivasi Lansia Tesis

Andira, Dita. 2010. Seluk Beluk Kesehatan Reproduksi Wanita. Yogyakarta : A Plus Books.

Aqila, Smart, 2010. Bahagia di Usia Menopause, Yogyakarta: A Plus Books.

Coopersmith. 2014. The antecedents of selfesteem. San Francisco : Freeman and Company

Dedhy Hamriadi Haruna dengan judul pengaruh terapi aktivitas kelompok terhadap kemampuan interaksi sosial lanjut usia di panti sosial tresna Wredha Gau Mabaji Gowa 2014.

Desmita. 2010. Psikologi Perkembangan Peserta Didik. Bandung: PT. Remaja Rosdakarya

Kemenkes RI. Profil Kesehatan Indonesia tahun 2014. Jakarta : Kemenkes RI; 2014. 
Keliat, B.A dan Akemat. 2012. Model Praktik Keperawatan Profesional Jiwa. Jakarta : EGC.

Koswara, 2014. Catatan Ilmu Kedokteran Jiwa. Bandung: Karya Putra Darwati.

Medical Record Puskesmas Sukamerindu Kota Bengkulu, 2017. Dat Lansia

Nirmala, 2013. Hidup Sehat dengan Menopause, Jakarta: Buku Populer Nirmala

Notoatmodjo, S, 2010. Metodologi Penelitian Kesehatan. Rineka Cipta. Jakarta

Mulyani, 2013. Kanker payudara dan Penyakit Menular Seksual Pada kehamilan. Yogyakarta: Nuha Medika

Padila. 2013. Asuhan Keperawatan Penyakit Dalam. Yogyakarta: Nuha Medika

Rachmawati, Imami Nur. 2016. Metodologi Penelitian Kualitatif Dalam Riset Keperawatan. Jakarta: Rajawali Press

Robins, 2012. Nursing Care Receiving Chemotherapy:
Rowlins dan Bock, 2012. Keperawatan Kesehatan Jiwa Komunitas CMHN (Basic Course). Jakarta :EGC

Prawirohardjo, Sarwono. 2013. Menopause dan Andropause. Jakarta : Yayasan Bina Pustaka Sarwono Prawirohardjo.

Stuart \& Laraia. 2010. Buku Saku Keperawatan Jiwa (terjemahan). Jakarta: EGC

Surya. 2016. Buku Asuhan Keperawatan Jiwa. Nuha Medika, Yogyakarta.

Tambunan, 2011. Keperawatan Jiwa Aplikasi Praktik Klinik. Yogyakarta: Graha Ilmu.

Yosep,Iyus. 2012. Keperawatan Jiwa. Bandung : PT. Refika Aditama

Yulizawati, 2016. Analisis Faktor Yang Berhubungan Dengan Peningkatan. Penggunaan Alat Kontrasepsi Dalam Rahim (AKDR). Jurnal Ilmiah. Kebidana 